\title{
ИССЛЕДОВАНИЕ ФАКТОРОВ, ВЛИЯЮЩИЕ НА СТРУКТУРУ КАПИТАЛА КОММЕРЧЕСКИХ БАНКОВ РФ И КНР
}

\section{RESEARCH OF FACTORS INFLUENCING THE CAPITAL STRUCTURE OF COMMERCIAL BANKS OF THE RUSSIAN FEDERATION AND CHINA}

Shen Binbin

A. Perfiliev

Summary. The state of development of the banking industry is an important condition and factor for the successful development of the country's economy. This article provides a brief comparative analysis of the capital structure of Russian and Chinese commercial banks, it was revealed that they have similar characteristics. As a research method, we used multiple linear regression analysis performed using R programming (R-Studio). The main purpose of the article is to study the internal and external factors that influence the formation of the capital structure of Chinese and Russian commercial banks. The empirical results showed that the total capital of the joint-stock commercial banks of the analyzed countries correlates with the capital adequacy ratio.

Keywords: commercial bank; capital adequacy ratio; capital structure, R-Studio, Russia, China.

\section{ИсслеАование структуры капитала} банков и факторов, влияюших на него

\section{Исследование структуры капитала банка}

C труктура капитала коммерческих банков может оказывать значительное влияние на операционные стратегии коммерческих банков, тем самым влияя на их прибыль. Теоретическая основа изучения структуры капитала банков основывается на методологии анализа структуры капитала предприятий. Рассмотрим мнения разных авторов, связанных с особенностью формирования структуры капитала коммерческих банков. Так, в 1958 году Модильяни и Миллер предложили: «Уровень долга никак не влияет на структуру капитала коммерческих банков». Впоследствии Модильяни и Миллер прояснили свою позицию: «из-за влияния факторов налогового щита капитал оптимальной структуры капитала компании основан на максимальном уровне долга» [1, с. 261]. Позже Миллер добавил, что эти теории применимы к банковской сфере в условиях несовершенной конкуренции на рынках. В 1973 году Крау и Литцен-

\author{
Шэнь Бинбин \\ Аспирант, Новосибирский государственный \\ университет, г. Новосибирск \\ shenbingbing724@gmail.com \\ Перфильев Александр Александрович \\ К.т.н, дочент, Новосибирский государственный \\ университет, г. Новосибирск
}

Аннотация. Состояние развития банковской отрасли - важное условие и фактор успешного развития экономики страны. В данной статье приведен краткий сравнительный анализ структуры капитала российских и китайских коммерческих банков, было выявлено, что у них есть схожие признаки. В качестве метода исследования был применен множественный линейный регрессионный анализ, выполненный с помощью $R$ программирования (R-Studio). Основная цель статьи — изучить внутренние и внешние факторы, влияющие на формирование структуры капитала китайских и российских коммерческих банков. Эмпирические результаты показали, что общий капитал акционерных коммерческих банков анализируемых стран коррелирует с коэффициентом достаточности капитала.

Ключевые слова: коммерческий банк; коэффициент достаточности капитала; структура капитала, R-Studio, Россия, Китай.

бергер представили теорию компромисса, влияющую на структуру капитала [2, с. 911]. В то время, как Харрис и Равив предлагали рассматривать теорию структуры капитала в виде «агентских издержек, информационной асимметрии, природы товаров и факторов корпоративного контроля» [3, с. 4]. Теория агентских отношений связывает выбор структуры капитала с существующими агентскими издержками из-за конфликта интересов между акционерами и менеджерами [4, с. 2]. Майерс и Майлуф считают, что выбор структуры капитала вызван информационной асимметрией между внутренним персоналом компании и внешними инвесторами [5, с. 187].

Гипотеза рыночного времени - это теория о том, как компании в экономике решают, использовать ли долевые или долговые инструменты для финансирования своих инвестиций $[6$, с. 19]. Согласно этой теории, время выхода на рынок оказывает влияние на выбор методов финансирования. Исследователь Такор изучил факторы роста банковского капитала, он предположил, что увеличение капитала коммерческих банков связано с увеличением кредитов, ликвидности и размера капитала [7]. 


\section{Исследование факторов, влияющих на структуру капитала банка}

Крылова Л.В подробно проанализировала процентную долю совокупного капитала банковского сектора Российской Федерации и его источники формирования, показав, что прирост капитала российских кредитных организаций за последние 10 лет представляет собой нераспределённую прибыль и сформированные из неё средства [8, с. 6]. Мирошниченко О.С. исследовал факторы, влияющие на рост структуры капитала российских банков с 2001 по 2010 гг. [9, с. 36]. В исследовании авторов можно встретить мнение о том, что в структуре капитала российских банков преобладает собственный капитал. Чтобы улучшить качество собственных средств, российские банки должны капитализировать прибыль. Михеева Н.Н. изучала взаимосвязь между структурой капитала банка и качеством активов банка. В некоторых работах можно встретить вывод том, что во время кризиса из-за недостаточного капитала многие банки обанкротились. Кроме того, на этот процесс повлияло повышенное внимание крупных регулирующих органов к качеству банковских активов [10, с. 32]. В работе Парусимова Н.И. указано, что структура капитала банка связана с системным риском. Чем выше системный риск, тем меньше спрос на ссуды в банковской сфере и снижается прибыль коммерческих банков [11, с. 318].

Основываясь на оригинальном исследовании Yang Tianfu, Zhang Qiang, основанного на финансовых отчётах 9 коммерческих банков Китая за 2010-2018 гг., можно говорить о том, что размер банка положительно коррелирует со структурой капитала, прибыльность и гарантийная стоимость активов не оказывают существенного влияния на структуру капитала банка, а процентная ставка по неработающим кредитам отклоняется от теоретических допущений [12, с. 44]. B работе Yang Di, где был проведен анализ результатов регрессионного исследования указано, что коэффициент достаточности капитала, прибыльность, коэффициент гарантии активов и качество активов оказывают значительное влияние на соотношение активов и пассивов как репрезентативные для структуры капитала. При этом, качество активов и прибыльность отрицательно коррелируют с соотношением долга к активам, а масштаб банка и стоимость гарантии положительно коррелируют с соотношением долга к активам, и влияние макрофакторов на него незначительно [13, с. 12]. В исследовании Dong Dawei есть информация о том, что коэффициент ликвидности положительно коррелирует с коэффициентом достаточности капитала. Поскольку увеличение коэффициента ликвидности снизит эффективность использования капитала акционерными коммерческими банками, акционерные коммерческие банки должны учитывать свои собственные обстоятельства при определении коэффициента ликвидности и выбирать оптимальный уровень между повышением коэффициента достаточности капитала и повышение эффективности использования капитала [14, с. 6]. Ding Mingming, Yu Chengyong в своем исследовании пришли к выводу о том, что значительная концентрация капитала не оказывает очевидного влияния на структуру капитала банков, и положительно влияет на банки, не прошедшие листинг [15, с. 25]. Dai Zhenya использует несколько методов линейной регрессии для выбора данных для 9 исследуемых банков при создании модели панельных данных. Путем эмпирического исследования установлено, что структура капитала банков, участвующих в анализе положительно коррелирует с масштабом, прибыльностью и макрофакторной инфляцией, отрицательно коррелирует с долей находящихся в обращении акций и не имеет существенной связи с ростом и риском активов [16, с. 83]. Lu Danqiang считает, что структура капитала коммерческих банков положительно коррелирует с размером их активов и возможностями роста, тогда как они отрицательно коррелируют с их прибыльностью, ликвидностью активов и безопасностью активов [17, с. 23].

\section{Регрессионный анализ структуры капита^а кИтайских и российских коммерческих банков}

\section{Построение модели и гипотезы}

Изначально было решено проверить три гипотезы.

Гипотеза 0: Структура капитала банка полностью определяется требованиями к нормативному капиталу и не имеет ничего общего с определяющими факторами структуры капитала.

Учитывая то, что нормативные требования к капиталу не могут полностью определить структуру банковского капитала, нулевая гипотеза была отвергнута.

В настоящем исследовании будет протестировано семь внутренних банковских детерминант: общие активы (TotalAssets), рентабельность активов (ROA), рентабельность активов (ROE), возможность гарантии активов (Coll), риск активов (риск), ставка выплаты дивидендов (Div)., коэффициент достаточности основного капитала (Tier1Ratio).

Зависимая переменная - это кредитное плечо банка. Статистически значимый результат приведет к выводу, что детерминанты проверенной структуры капитала связаны с изменениями в капитале. Противоположный результат поставит эту гипотезу под сомнение.

Гипотеза 1: Детерминанты банковского сектора оказывают влияние на структуру капитала банков. 
Таблица 1. Основные показатели для выборок из коммерческих банков КНР

\begin{tabular}{|l|l|l|}
\hline \multicolumn{1}{l|}{} & Показатели для выборок из коммерческих банков КНР & Сокращение \\
\hline 2 & Размер активов (в тысячах долларов США) & TotalAssets \\
\hline 3 & Рентабельность активов & ROA \\
\hline 4 & Коэффициент рентабельности собственного капитала & ROE \\
\hline 5 & Стоимость обеспечения & Coll \\
\hline 6 & Риск активов & risk \\
\hline 7 & Норма выплаты дивидендов & Div \\
\hline 8 & Капитал первого уровня & Tier1Ratio \\
\hline 9 & Доходность акций & return \\
\hline 10 & Рыночная доходность индекса & Mreturn \\
\hline 11 & Риск фондового рынка & Mrisk \\
\hline 12 & ВВП & GDP \\
\hline
\end{tabular}

Источник: Составлено автором

Используем формулу, чтобы проверить первую гипотезу:

$$
\begin{aligned}
& \mathrm{L}_{\mathrm{i}, \mathrm{t}}=\mathrm{f}\left(\operatorname{Total}_{\text {Assets }} \mathrm{t,-1}, \mathrm{ROA}_{\mathrm{i}, \mathrm{t}-1}, \mathrm{ROE}_{\mathrm{i}, \mathrm{t}-1}, \operatorname{Coll}_{\mathrm{i}, \mathrm{t}-1},\right. \\
& \text { risk } \left._{\mathrm{i}, \mathrm{t}-1}, \operatorname{Div}_{\mathrm{i}, \mathrm{t}}, \text { Tier1Ratio }_{\mathrm{i}, \mathrm{t}}\right)
\end{aligned}
$$

$\mathrm{L}_{\mathrm{i}, \mathrm{t}}$ - это финансовый рычаг банка і в течение $\mathrm{t}$, который определяется как отношение собственного капитала к активам.

Гипотеза 2: Доходность капитала (доходность) имеет важную объясняющую силу для структуры капитала банков, а совокупное влияние стандартных факторов, определяющих структуру капитала, незначительно.

Для проверки второй гипотезы доходность акций включается в регрессию и проверяется с помощью финансового рычага. Чтобы проверить гипотезу 2, была применена формула:

$$
\begin{aligned}
& \mathrm{L}_{\mathrm{i}, \mathrm{t}}=\mathrm{f}\left(\text { TotalAssets }_{\mathrm{i}, \mathrm{t}-1}, \mathrm{ROA}_{\mathrm{i}, \mathrm{t}-1}, \mathrm{ROE}_{\mathrm{i}, \mathrm{t}-1}, \text { Coll }_{\mathrm{i}, \mathrm{t}-1}\right. \text {, } \\
& \text { risk } \left._{\mathrm{i}, \mathrm{t}-1}, \text { Div }_{\mathrm{i}, \mathrm{t}} \text {, Tier1Ratio }_{\mathrm{i}, \mathrm{t}} \text {,return }_{\mathrm{i}, \mathrm{t}-1}\right)
\end{aligned}
$$

Гипотеза 3: Макроэкономические факторы имеют важную объясняющую силу для структуры капитала банков, в то время как общее влияние стандартных детерминант структуры капитала незначительно.

Третья гипотеза связана с влиянием макроэкономических факторов на структуру капитала банков. Дело в том, что макроэкономические факторы могут объяснить изменения в структуре капитала. Чтобы проверить эту гипотезу, влияние макрофакторов было включено в регрессию, и был протестирован финансовый рычаг. Необходимо протестировать четыре макроэкономиче- ские банковские детерминанты: доходность рыночного индекса, риск фондового рынка, ВВП, инфляцию и дефлятор ВВП (годовой процент).

Чтобы проверить гипотезу 3, было применено уравнение вида:

$$
\begin{aligned}
& \mathrm{L}_{\mathrm{i} . \mathrm{t}}=\mathrm{f}\left(\text { TotalAssets }_{\mathrm{i}, \mathrm{t}-1}, \cdots, \text { Tier1 }_{\text {Ratio }}, \mathrm{t},\right. \\
& \operatorname{return}_{\mathrm{i}, \mathrm{t}-1}, \text { Mreturn }_{\mathrm{i}, \mathrm{t}}, \text { Mrisk }_{\mathrm{i}, \mathrm{t}} \text {, } \\
& \left.\mathrm{GDP}_{\mathrm{i}, \mathrm{t}}, \text { deflator }_{\mathrm{i}, \mathrm{t}}\right)
\end{aligned}
$$

\section{Выбор переменных \\ и истОЧнИкИ $\triangle$ ӘНных}

Выбор переменных основывается как на исследованиях Gropp и Haider [18, с. 587], Frank и Goyal [19, с. 217], так и на основании объективной реальности (см. Таблица 1).

\section{Источники данных}

Все финансовые отчёты банка взяты с веб-сайта Orbis, выборка включает коммерческие банки, представленные в Североамериканской системе отраслевой классификации (NAICS). Мы провели всесторонний анализ выборки коммерческих банков в Китае и России и обнаружили, что небольшие банки могут повлиять на окончательный результат. Нами была уменьшена выборка в соответствии с реальной ситуацией. В исследовании применен язык программирования R-Studio для изучения данных 20 коммерческих банков Китая и 17 коммерческих банков России за 2011-2019 г. (см. Таблица 2 и 3). В дополнение к этой информации были также собраны макроэкономические данные. База данных Всемирного банка (IBRD) предоставила историческую информацию 
Таблица 2. Ключевые показатели выборки российских коммерческих банков

\begin{tabular}{|l|l|l|l|l|l|}
\hline & Min. & Median & Mean & Max & sdata \\
\hline Lev & -0.72063 & 0.11665 & 0.13194 & 0.53973 & $1.11 \mathrm{E}-01$ \\
\hline TotalAssets & 30953 & 2540817 & 33440083 & 556393068 & $9.41 \mathrm{E}+07$ \\
\hline ROA & -0.81141 & 0.012457 & 0.005552 & 0.39001 & $6.92 \mathrm{E}-02$ \\
\hline ROE & -8.470209 & 0.071664 & -0.02216 & 1.132367 & $6.75 \mathrm{E}-01$ \\
\hline Mrisk & 0.03932 & 0.05958 & 0.0666 & 0.10626 & $2.08 \mathrm{E}-02$ \\
\hline Coll & 0.9539 & 0.9989 & 0.9963 & 1 & $6.31 \mathrm{E}-03$ \\
\hline Div & 0 & 0 & 0.001315 & 0.274752 & 0.01787 \\
\hline Tier1Ratio & 4.4 & 11.3 & 14.07 & 97.6 & 12.87278 \\
\hline return & -0.07351 & 0.00543 & 0.01394 & 0.25538 & 0.051023 \\
\hline risk & 0.01347 & 0.0883 & 0.12221 & 0.8721 & 0.130422 \\
\hline Mreturn & -0.0459673 & 0.0003165 & 0.0019103 & 0.0369272 & 0.024355 \\
\hline GDP & $1.277 \mathrm{E}+12$ & $1.7 \mathrm{E}+12$ & $1.761 \mathrm{E}+12$ & $2.292 \mathrm{E}+12$ & $3.46 \mathrm{E}+11$ \\
\hline deflator & 2.844 & 7.25 & 7.554 & 24.46 & 5.141412 \\
\hline
\end{tabular}

Источник: Составлено автором

Таблица 3. Ключевые показатели выборки китайских коммерческих банков

\begin{tabular}{|l|l|l|l|l|l|}
\hline & Min. & Median & Mean & Max & sdata \\
\hline Lev & 0.02332 & 0.06887 & 0.08602 & 0.98243 & $1.10 \mathrm{E}-01$ \\
\hline TotalAssets & $8.60 \mathrm{E}+04$ & $7.72 \mathrm{E}+07$ & $4.36 \mathrm{E}+08$ & $4.31 \mathrm{E}+09$ & $8.22 \mathrm{E}+08$ \\
\hline ROA & -0.089872 & 0.011248 & 0.012143 & 0.111484 & $1.02 \mathrm{E}-02$ \\
\hline ROE & -0.1605 & 0.1335 & 0.1342 & 0.2583 & $4.68 \mathrm{E}-02$ \\
\hline Mrisk & 0.02309 & 0.0515 & 0.05584 & 0.12116 & $2.66 \mathrm{E}-02$ \\
\hline Coll & 0.91 & 0.9995 & 0.9981 & 1 & $7.77 \mathrm{E}-03$ \\
\hline Div & 0 & 0.229 & 0.2043 & 3.3756 & $2.42 \mathrm{E}-01$ \\
\hline Tier1Ratio & 6.47 & 10.32 & 10.51 & 15.54 & $1.46 \mathrm{E}+00$ \\
\hline return & -0.11406 & 0.00269 & 0.00076 & 0.12918 & $3.24 \mathrm{E}-02$ \\
\hline risk & 0 & 0.06676 & 0.07829 & 0.39508 & $4.55 \mathrm{E}-02$ \\
\hline Mreturn & -0.023735 & 0.008354 & 0.003487 & 0.040518 & $1.84 \mathrm{E}-02$ \\
\hline GDP & $7.55 \mathrm{E}+12$ & $1.12 \mathrm{E}+13$ & $1.14 \mathrm{E}+13$ & $1.43 \mathrm{E}+13$ & $2.03 \mathrm{E}+12$ \\
\hline deflator & -0.002944 & 2.16337 & 2.431725 & 8.075684 & $1.93 \mathrm{E}+00$ \\
\hline
\end{tabular}

Источник: Составлено автором

о росте реального ВВП и уровне инфляции для каждой страны.

\section{(3) Анализ данных с применением R-Studio}

В таблице представлена описательная статистика для основных факторов и зависимых переменных. Модель исследования выглядит следующим образом:

$\operatorname{Lev}_{\mathrm{i}, \mathrm{t}}=\beta_{0}+\beta_{1} \log (\text { TotalAssets })_{\mathrm{i}, \mathrm{t}-1}+\beta_{2} \mathrm{ROA}_{\mathrm{i}, \mathrm{t}-1}+\beta_{3}$ ROE $_{\mathrm{i}, \mathrm{t}-1}+$ $\beta_{4}$ Coll $_{\mathrm{i}, \mathrm{t}-1}+\beta_{5}$ risk $_{\mathrm{i}, \mathrm{t}-1}+\beta_{6} \operatorname{Div}_{\mathrm{i}, \mathrm{t}}+\beta_{7}$ Tier1Ratio $_{\mathrm{i}, \mathrm{t}}+\beta_{8}$ return $_{\mathrm{i}, \mathrm{t}-1}+$

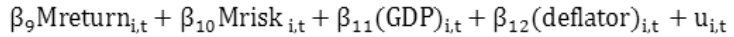

Из таблиц 2 и 3 видно, что факторы, влияющие на структуру капитала банковской отрасли Россия и Китая схожи. Согласно данным таблиц 2 и 3, показатель ROA оказывает отрицательное влияние на эмпирические результаты, хотя согласно теоретическим положе- ниям он должен показывать положительное значение. Между показателем доходности инвестиций в России и средним значением существует большое отклонение, потому что финансовый рынок России не так стабилен, как китайский. Взаимосвязь между финансовым рычагом и дивидендами соответствует агентской теории, и влияние дивидендов банков на структуру капитала банков Китая и России незначительно. Очевидно, это связано с низкой дивидендной доходностью банковских вложений, которая намного уступает другим листинговым компаниям.

Сравнивая результаты в Таблице 4, можно обнаружить, что структура капитала российских коммерческих банков положительно коррелирует с ROA. Для структуры капитала российских коммерческих банков, помимо ROA, значительное значение отрицательной 
Таблица 4. Результаты регрессии выборки российских коммерческих банков

\begin{tabular}{|l|l|l|l|l|}
\hline Параметры & Коэффициенты & $\begin{array}{l}\text { Стандартное откло- } \\
\text { нение тестовое значе- } \\
\text { ние }\end{array}$ & $\operatorname{Pr}(>|\mathbf{t}|)$ \\
\hline (Intercept) & 0.187911 & 1.02939 & 0.183 & 0.85571 \\
\hline log(TotalAssets) & -0.00876 & 0.001957 & -4.474 & 0.000031 \\
\hline ROA & 4.133924 & 0.725656 & 5.697 & $3.07 \mathrm{E}-07$ \\
\hline ROE & -0.42995 & 0.098552 & -4.363 & $4.61 \mathrm{E}-05$ \\
\hline Mrisk & 0.003782 & 0.230162 & 0.016 & 0.98694 \\
\hline Coll & -1.20083 & 0.669191 & -1.794 & 0.07732 \\
\hline Div & 0.627604 & 0.73592 & 0.853 & 0.39685 \\
\hline Tier1Ratio & 0.004289 & 0.000551 & 7.78 & $6.54 \mathrm{E}-11$ \\
\hline return & 0.128481 & 0.15221 & 0.844 & 0.40166 \\
\hline risk & -0.17887 & 0.05536 & -3.231 & 0.00192 \\
\hline Mreturn & -0.14005 & 0.196883 & -0.711 & 0.4794 \\
\hline log(GDP) & 0.043538 & 0.023753 & 1.833 & 0.07133 \\
\hline deflator & -0.00101 & 0.001077 & -0.937 & 0.35242 \\
\hline Residual standard error: & 0.0299 & Adjusted R2 & & \\
\hline Multiple R2 & 0.7879 & p-value & & 0.7494 \\
\hline F-statistic & 20.43 & & $<2.2 \mathrm{e}-16$ \\
\hline
\end{tabular}

Источник: Составлено автором

Таблица 5. Результаты регрессии выборки китайских коммерческих банков

\begin{tabular}{|c|c|c|c|c|}
\hline Параметры & Коэффициенты & $\begin{array}{l}\text { Стандартное откло- } \\
\text { нение }\end{array}$ & $\begin{array}{l}\text { t тестовое значе- } \\
\text { ние }\end{array}$ & $\operatorname{Pr}(>|t|)$ \\
\hline (Intercept) & 0.082997 & 0.241082 & 0.344 & 0.731023 \\
\hline $\log$ (TotalAssets) & -0.001 & 0.0002 & -5.004 & $1.27 \mathrm{E}-06$ \\
\hline ROA & 3.867729 & 0.189845 & 20.373 & $2.00 \mathrm{E}-16$ \\
\hline $\mathrm{ROE}$ & -0.36973 & 0.016977 & -21.778 & $2.00 \mathrm{E}-16$ \\
\hline Mrisk & -0.00699 & 0.018553 & -0.377 & 0.706711 \\
\hline Coll & -0.27942 & 0.23306 & -1.199 & 0.232039 \\
\hline Div & 0.003362 & 0.002093 & 1.606 & 0.109904 \\
\hline Tier1Ratio & 0.002058 & 0.000235 & 8.776 & 9.47E-16 \\
\hline return & 0.00293 & 0.012005 & 0.244 & 0.807433 \\
\hline risk & 0.003211 & 0.006888 & 0.466 & 0.641598 \\
\hline Mreturn & -0.01481 & 0.021239 & -0.697 & 0.486418 \\
\hline $\log (G D P)$ & 0.008917 & 0.002604 & 3.424 & 0.000755 \\
\hline deflator & 0.000298 & 0.000307 & 0.973 & 0.331799 \\
\hline Residual standard error: & \multicolumn{4}{|l|}{\begin{tabular}{|l|l|} 
& 0.003493 \\
\end{tabular}} \\
\hline Multiple R2 & \multicolumn{3}{|c|}{ Adjusted R2 } & 0.8944 \\
\hline F-statistic & \multicolumn{3}{|c|}{ p-value } & $<2.2 \mathrm{e}-16$ \\
\hline
\end{tabular}

Источник: Составлено автором

корреляции имеет стоимость обеспечения. Помимо вышеперечисленных факторов, дивиденды банков имеют значительную корреляцию со структурой капитала российских коммерческих банков.

Сравнивая результаты в Таблице 5, можно обнаружить, что структура капитала китайских коммерческих банков положительно коррелирует с ROA. Для структуры капитала китайских коммерческих банков, помимо
ROA, стоимость обеспечения имеет значительную отрицательную корреляцию. Помимо перечисленных выше факторов влияния, ВВП также имеет значительную корреляцию со структурой капитала китайских коммерческих банков.

В Таблицах 6 и 7 представлена матрица корреляции между независимой и зависимой переменной. Высокая положительная корреляция между ROA и ROE объясня- 
Таблица 6. Корреляция между 12 переменными российских коммерческих банков

\begin{tabular}{|c|c|c|c|c|c|c|c|c|}
\hline & Lev & TA & ROA & ROE & Mrisk & Coll & Div & Tier1 \\
\hline Lev & 1.000 & & & & & & & \\
\hline TA & -0.211 & 1.000 & & & & & & \\
\hline $\mathrm{ROA}$ & 0.156 & 0.288 & 1.000 & & & & & \\
\hline ROE & -0.037 & 0.343 & 0.933 & 1.000 & & & & \\
\hline Mrisk & -0.107 & 0.044 & -0.127 & -0.117 & 1.000 & & & \\
\hline Coll & 0.179 & -0.267 & 0.114 & 0.106 & -0.270 & 1.000 & & \\
\hline Div & -0.081 & 0.224 & 0.000 & 0.024 & 0.173 & 0.026 & 1.000 & \\
\hline Tier1 & 0.765 & -0.202 & 0.075 & -0.053 & -0.107 & 0.219 & -0.066 & 1.000 \\
\hline
\end{tabular}

Источник: Составлено автором

Таблица 7. Корреляция между 12 переменными китайских коммерческих банков

\begin{tabular}{|l|l|l|l|l|l|l|l|l|}
\hline & Lev & TA & ROA & ROE & Mrisk & Coll & Div & Tier1 \\
\hline Lev & 1.000 & & & & & & & \\
\hline TA & 0.071 & 1.000 & & & & & & \\
\hline ROA & -0.112 & 0.287 & 1.000 & & & & & \\
\hline ROE & -0.540 & 0.182 & 0.868 & 1.000 & & & & \\
\hline Mrisk & -0.144 & 0.058 & 0.279 & 0.262 & 1.000 & & & \\
\hline Coll & -0.189 & -0.067 & -0.091 & 0.036 & 0.031 & 1.000 & & \\
\hline Div & 0.144 & 0.010 & 0.077 & 0.049 & 0.052 & -0.057 & 1.000 & \\
\hline Tier1 & 0.687 & 0.381 & 0.072 & -0.210 & -0.078 & -0.033 & 0.226 & 1.000 \\
\hline
\end{tabular}

Источник: Составлено автором

ется двумя фактами: оба показателя зависят от прибыли, с одной стороны, они зависят от активов, с другой от финансового рычага.

\section{Зак^ючение}

Банковская система Китая основывается на растущей и управляемой экономике. Китайское правительство заинтересовано в постоянном анализе механизма, который влияет на работу банковской системы, поэтому периодически вводятся рыночные элементы, чтобы контролировать как банковскую систему, так и экономику страны в целом. В России банковская система находится в затяжной рецессии, что несколько затрудняет выявле- ние в ней определённых тенденций. Однако обе страны придают большое значение формированию наилучшей структуры капитала коммерческих банков.

В Китае и в России факторы, оказывающие влияние на структуру капитала банковского сектора во многом схожи. Во-первых, структура капитала зависит от размера банка. Во-вторых, на структуру капитала коммерческих банков оказывают влияние рентабельность активов (ROA), уровень BBП, показатель достаточности основного капитала. В-третьих, прибыль от рыночных фондовых индексов мало влияет на структуру капитала как на китайские, так и на российские коммерческие банки.

\section{ЛИТЕРАТУРА}

1. Modigliani F., Miller M.H. The Cost of Capital, Corporation Finance and the Theory of Investmen. // The American Economic Review. 1958. June. P. $261-297$.

2. Kraus, A. and Litzenberger, R.H. A State-Preference Model of Optimal Financial Leverage // Journal of Finance, 1973, vol. 28, issue 4, $911-922$.

3. Harris, M. and Raviv, A. The Theory of Capital Structure // Journal of Finance, 1991(46), 297-355.

4. Michael C. Jensen, A theory of the firm: governance, residual claims and organizational forms // Journal of Financial Economics (JFE), Vol. 3, No. 4, 1976.

5. Stewart C. Myers and Nicholas S. Majluf. Corporate financing and investment decisions when firms have information that investors do not have // Journal of Financial Economics, 1984, vol. 13, issue 2, 187-221.

6. Baker M., Wurgler J. Market timing and capital structure //The journal of finance, 2002, 57(1), 1-32.

7. Thakor A.V. Bank capital and financial stability: an economic trade-off or a Faustian bargain //Annual Review of Financial Economics, 2014, vol. 6, issue 1, 185-223.

8. Крылова Л.В. Источники и факторы роста капитала российских банков // Финансовая аналитика: проблемы и решения. 2015. № 35 (269). С. 2-10. 
9. Мирошниченко 0.С. Развитие капитальной базы российских банков // Финансы и кредит. 2011. № 41 (473). С. $36-47$.

10. Михеева Н.Н. Капитализация банков как фактор роста экономики // Интеллект. Инновации. Инвестиции. 2016. № 11. С. 32-36.

11. Парусимова Н.И. Банковское дело в условиях роста неопределенности // Вестник Оренбургского государственного университета. № 4 (179). С. $318-321$.

12. Yang Tianfu, Zhang Qiang. An Empirical Study on the Influencing Factors of the Capital Structure of China's Listed Commercial Banks // China Business Review, 2020(19): 44-48. (in China)

13. Yang Di. Research on the Capital Structure and Influencing Factors of City Commercial Banks // Hebei University, 2016. (in China)

14. Dong Dawei. Research and analysis on the influencing factors of the capital structure of China's joint-stock commercial banks //Anhui Agricultural University, 2015. (in China)

15. Ding Mingming, Yu Chengyong. The influencing factors of the capital structure of my country's commercial banks-research based on OLS regression and quantile regression //Journal of Nanjing University of Finance and Economics, 2015(01): 25-32. (in China)

16. Dai Zhenya. An Empirical Analysis of the Influencing Factors of the Capital Structure of China's Listed Bank. //Journal of Hefei University (Social Science Edition), 2014, 31(02): 83-87. (in China)

17. Lu Danqiang. An Empirical Analysis of the Influencing Factors of the Capital Structure of China's Listed Commercial Bank. //Journal of Wuxi Vocational and Technical College of Commerce, 2013, 13(02): 23-27. (in China)

18. Reint Gropp, Florian Heider. The determinants of bank capital structure // Review of Finance. 2010. T. 14. № 4. C. 587-622.

19. Murray Z. Franka, Vidhan K. Goyal. Testing the pecking order theory of capital structure // Journal of Financial Economics, 2003(67),217-248.

() Шэнь Бинбин ( shenbingbing724@gmail.com ), Перфильев Александр Александрович.

Журнал «Современная наука: актуальные проблемы теории и практики»

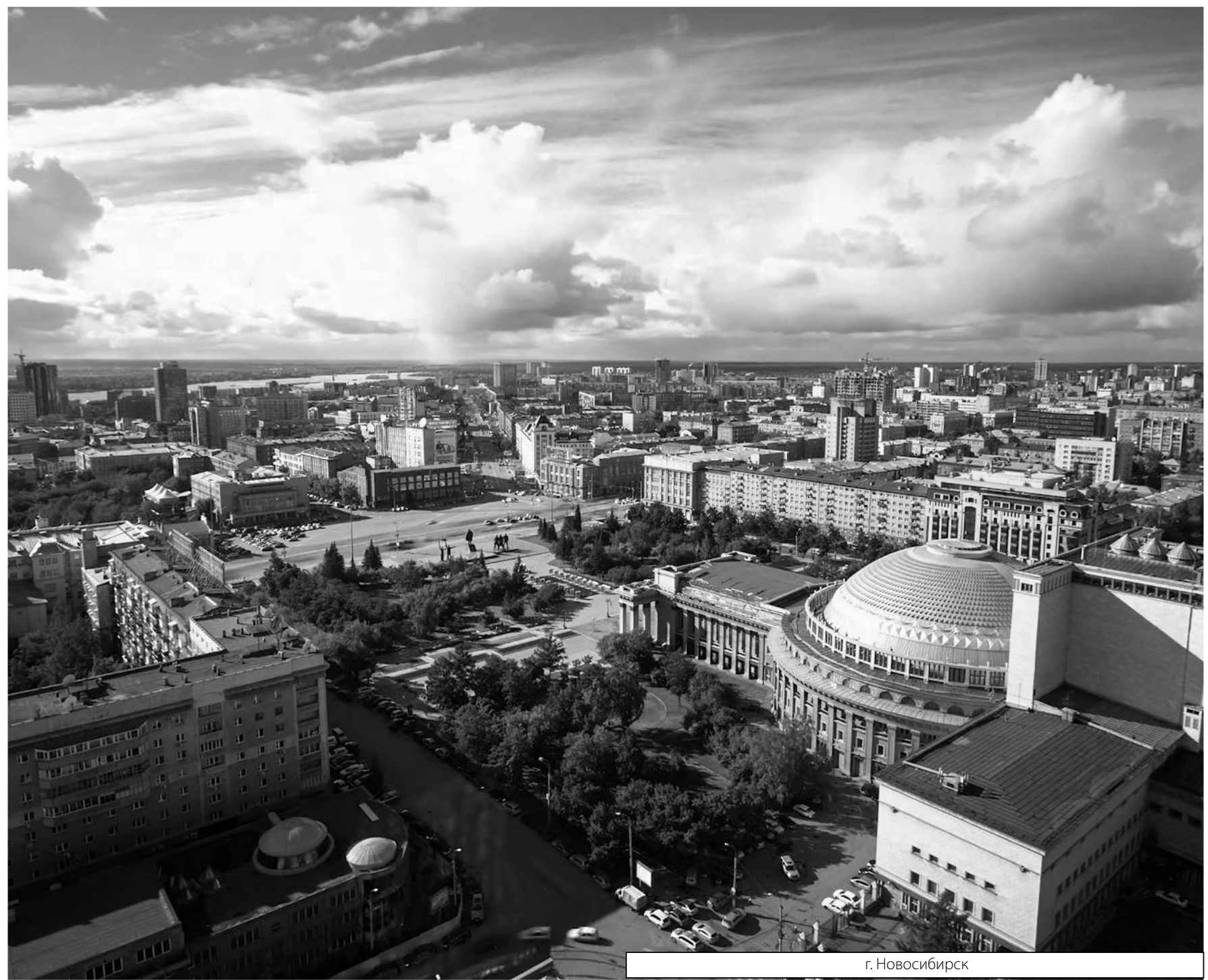

